\title{
$\begin{array}{lllllllll}\mathrm{I} & \mathrm{N} & \mathrm{S} & \mathrm{T} & \mathrm{I} & \mathrm{T} & \mathrm{U} & \mathrm{T} & \mathrm{E}\end{array}$
}

\section{Rural America in the 21st Century: Perspectives from the Field}

\section{Prepared for the National Rural Assembly, June 2007}

$\mathrm{R}$ ural America is undergoing sweeping demographic, economic, and environmental changes. Whether they are harnessed effectively will depend on federal and state policies and community actions over the next decade.

To address these challenges and foster an energized, informed movement to improve rural policies at the federal level, 300 rural leaders from across the United States will gather in June 2007 at the first annual National Rural Assembly. The assembly, convened by the Ford and W.K. Kellogg Foundations, will strengthen rural America by giving its leaders a platform for their ideas, raising the visibility of rural issues, organizing a national network of rural interests, and developing specific strategies to advance rural policy initiatives.

\section{Defining Issues, Broadening the Network, Developing Policy}

To support the development of the National Rural Assembly, the Carsey Institute at the University of New Hampshire conducted a series of interviews and policy roundtables in March and April 2007 with more than 80 Ford Foundation rural program grantees and other stakeholders. The interviews solicited perspectives on critical rural issues and public policy solutions. The roundtables-held in the Northeast, Southwest, and Central Appalachia-tested the findings from the interviews, stimulated additional thinking on issues and strategies, and strengthened three key regional rural networks. Overall, the interviews and roundtables will inform the agenda for the National Rural Assembly. (Lists of interviewees and participants in regional roundtables are included at the end of this report.) This report offers a synthesis of what we learned about the central issues in rural areas across the country today.

\section{Interview Questions for National Rural}

\section{Assembly 2007}

\section{Background}

1. What types of rural communities are in your area, or which types of communities do you work with?

\section{Identifying Critical Rural Issues}

2. What do you find to be the main forces-economic, political, social, cultural, or environmental-that drive change in the rural communities where you work?

3. What issues regularly resurface in these rural communities? What are the opportunities?

Finding Policy Solutions

4. What are the most promising strategies to meet these challenges and opportunities? What policies are effective and what policies stand in the way-or what new legislation is needed - to advance the most promising strategies?

5. To what extent do you and your colleagues actively work on policy issues? To what extent do you talk to state or national legislators or their staff about policies and programs to benefit rural communities?

6. What would help you and your colleagues be more effective in the policy arena? 


\section{CARSEY INSTITUTE}

Figure 1. AMENITY-RICH AREAS ARE GROWING AND LIKELY TO GROW MORE OVER THE NEXT DECADE

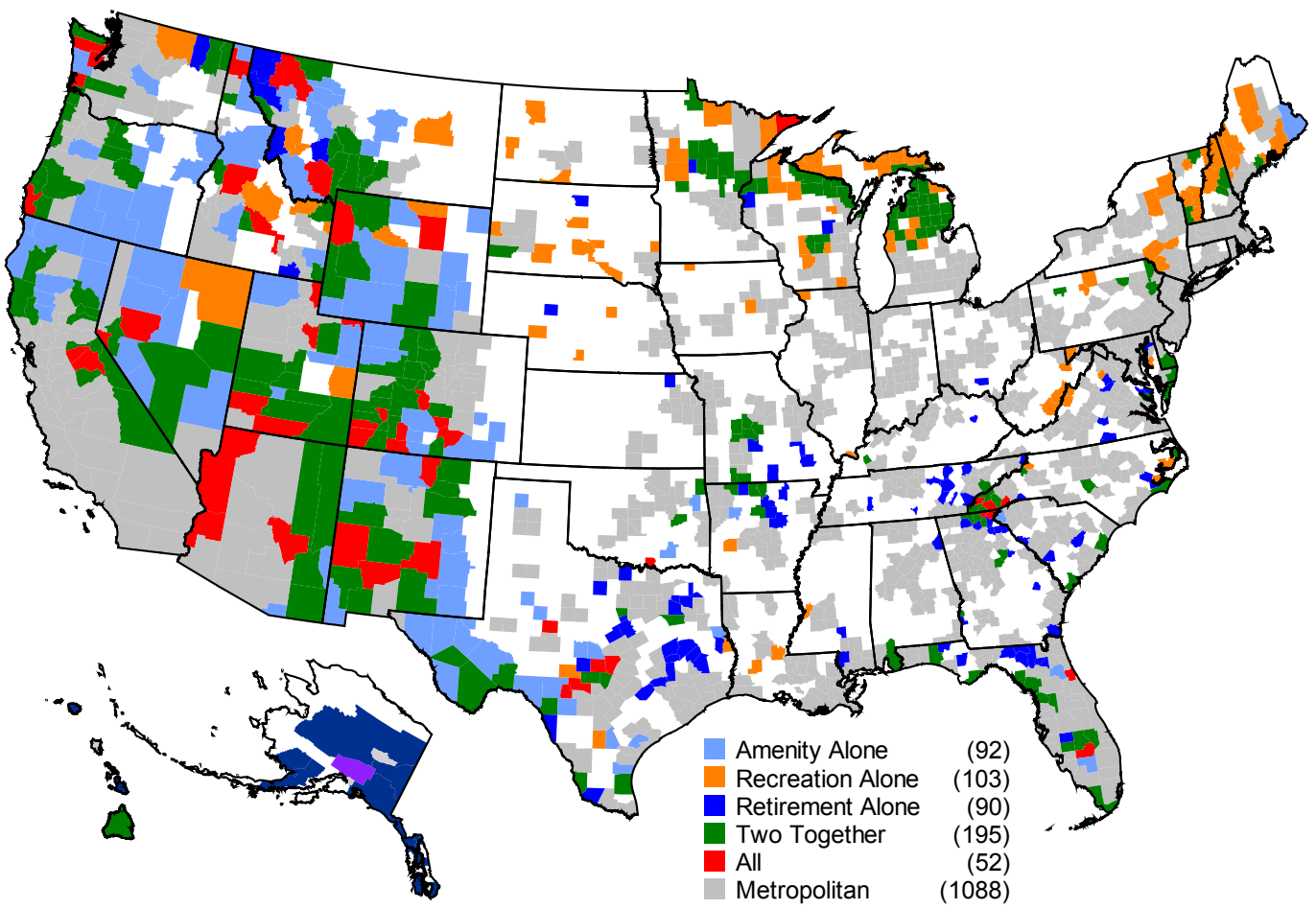

Source: Beale and Johnson, 2002; McGranahan, 1999; USDA Economic Research Service, 2004.

Figure 2. Persistent POPUlation loss Plagues other RESOURCE DEPENDENT AREAS

Loss is concentrated in the Great Plains, parts of the Corn Belt, the lower Mississippi Valley, and Appalachia

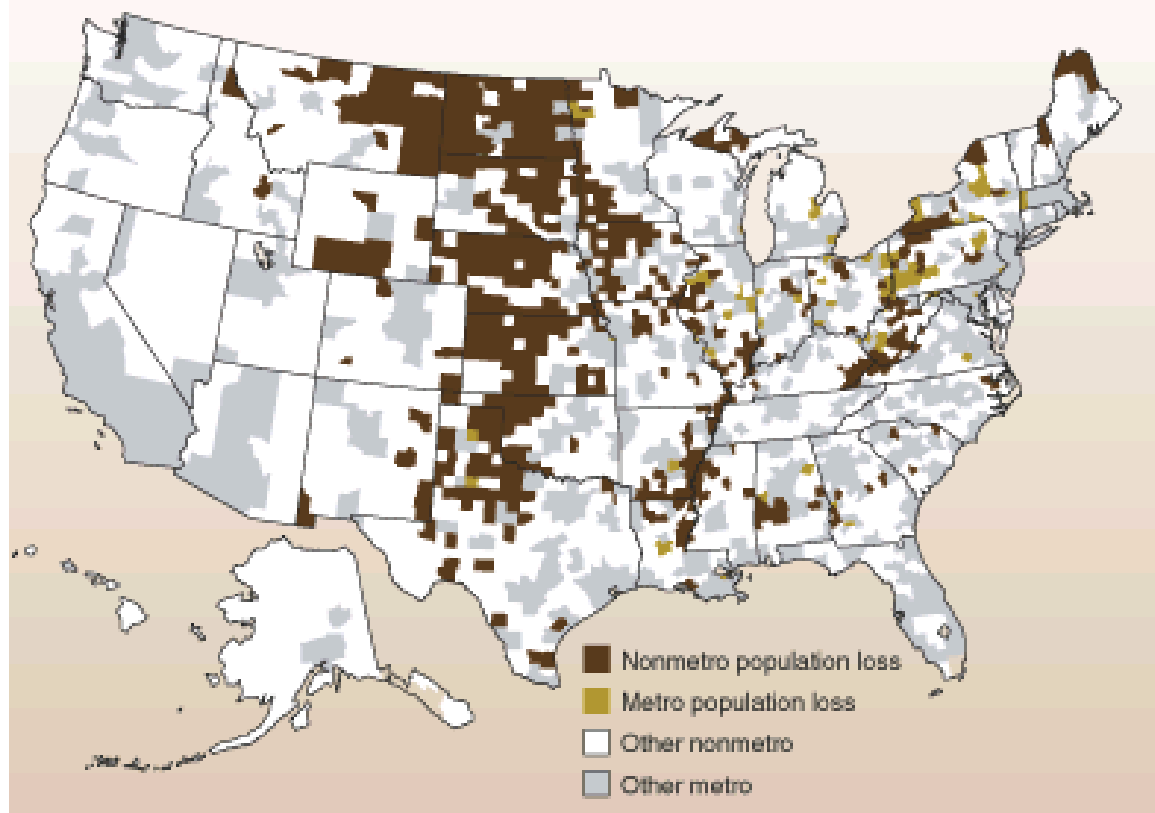


Figure 3. CORRESPONDING LOW EDUCATION DISADVANTAGES WHOLE REGIONS IN THE NEW ECONOMY

Low-education counties, 2000

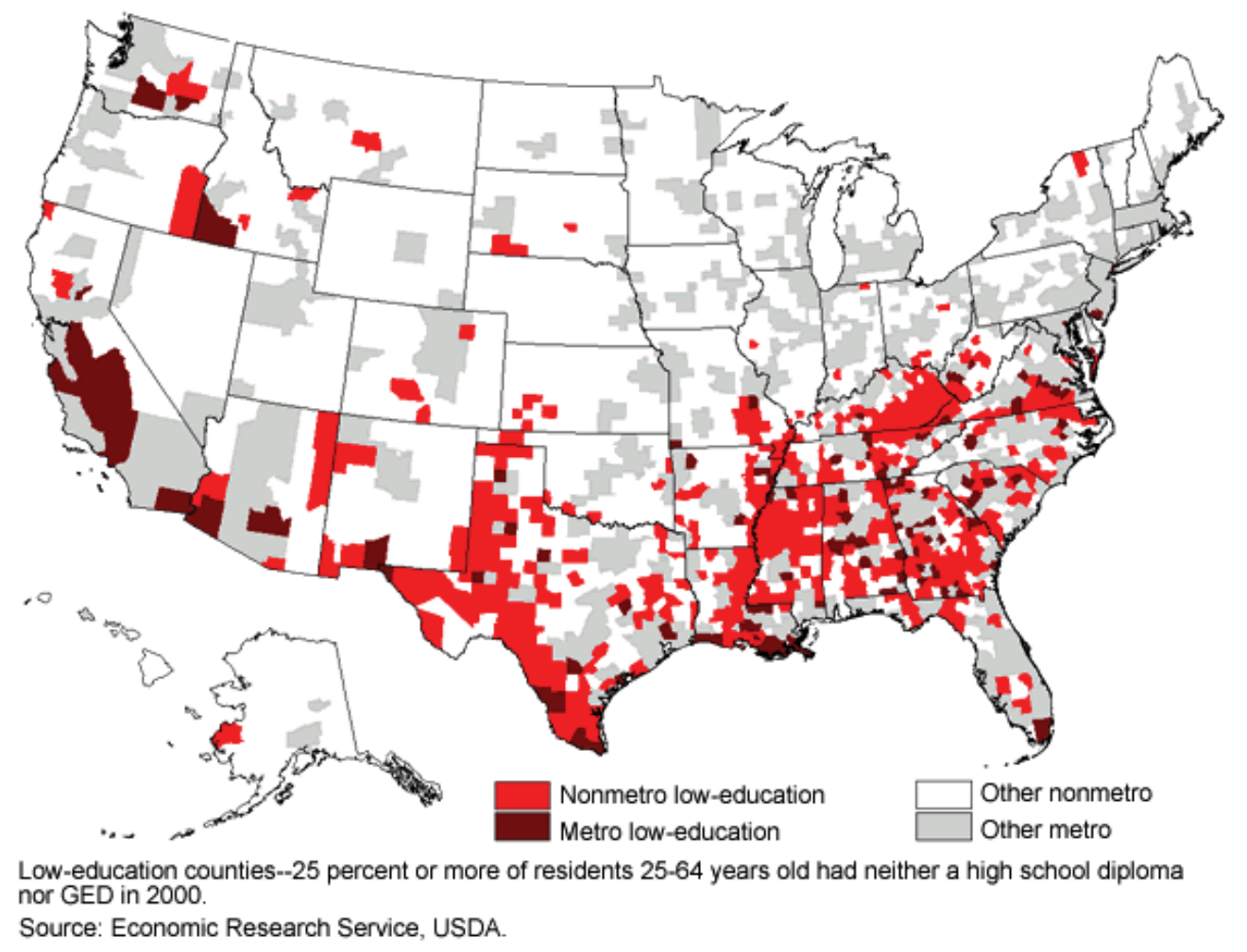

\section{Core Issues in Rural America Today}

Today, there are three rural Americas, sometimes distinct and sometimes overlapping, each with its own challenges:

- Amenity-rich areas, which are growing as Baby Boomers retire, as more people buy second homes, and as "footloose professionals" choose to settle in small towns with rich natural amenities or proximity to large cities

- Declining resource-dependent areas, which can no longer rely on agriculture, timber, mining, or related manufacturing industries to support a solid blue-collar middle class

- Chronically poor communities, where decades of resource extraction and underinvestment have left a legacy of poverty, low education, and broken civic institutions.

These conditions influence how communities address the issues they face amid a changing rural landscape. Amenity- rich areas, for example, must work to ensure the successful integration of newcomers and long-time residents, avoid a two-tier system of wealthy residents and those who serve them, and protect the natural environment that attracted the amenity migrants. Communities facing declining economies must develop programs to ameliorate the impact of economic decline and innovate to stem future population and job loss. Chronically poor communities must expand their human and social capital to break the chain of persistent poverty.

The rural practitioners interviewed for this project identified five main issues driving change in rural America:

- Demographic transitions

- Changing economic conditions

- Changing patterns of investment and resource distribution

- Challenges facing community institutions and civic leaders

- Environmental challenges 


\section{Demographic Transitions}

Migration into and out of rural communities plays an important role in determining the demographic characteristics of rural America. Across many parts of rural America, the steady exodus of young adults affects the dynamics of the labor force and the vibrancy of a community's cultural, intellectual, and social life. However, the long-standing exodus from rural to urban has shifted in some areas, and net migration is now fueling growth in many rural communities. ${ }^{1}$ This rural growth results from the relentless outward sprawl of metropolitan areas and from amenity migration. In some regions, older residents are moving into rural areas, drawn by natural amenities, recreation opportunities, and quality of life. Increasingly, these are Baby Boomers who are choosing to settle or retire in quieter, less-congested places. These new residents bring new experience, skills, and financial resources to rural areas, but they can also contribute to sprawl and create new pressures on the cost of living, especially affordable housing. Older residents also require additional health care and transportation needs that can place added burdens on limited services and resources. The challenge for local policymakers in amenity-rich areas is to ensure the successful integration of newcomers with long-time residents. Communities must work to secure livable wages and affordable housing for long-time residents, prevent actual or virtual "gated communities" that exacerbate inequality and protect the natural environment.

Rural communities also are experiencing significant migration gains fueled by Hispanics and other "new Americans" in response to low-wage employment opportunities, as well as affordable housing and a relatively low cost of living. These new immigrants often bring vitality and young people to communities. However, their arrival also introduces tensions associated with the underlying transformation of the rural economy and the new social and cultural differences. Communities must ensure that a growing foreign-born workforce is well integrated into neighborhoods and community life. Here, inclusive civic organizations are critical to both building a new rural middle class and preserving the old one.

The effects of migration are far-reaching for rural America, as the following quotes and summaries of the interviews with rural practitioners reveal.

\section{Perspectives from the field}

The loss of population, especially the young

- The decline of the rural manufacturing industries and the continuing consolidation of agriculture mean fewer good jobs available for young adults, forcing them to seek employment elsewhere. The more remote rural places are seeing the greatest population loss, leaving some communities to "die a slow death."

- Many rural communities have far fewer young families today, changing the feel and culture of the community and making it difficult to maintain quality schools and other institutions.

Our communities are 25 percent older than the rest of the nation. There is a significant decrease in population aged 30-39 and their children. With it, the social infrastructure is declining. We have fewer kids in school and no one to coach Little League.

- Rural practitioner, Midwest region

\section{Quality of life}

- Technological advances are creating employment opportunities in more rural and remote areas for those who might not have considered living in these locales. Areas within commuting distance of urban and suburban jobs are also growing.

- Many areas with natural amenities are booming, with rising real estate sales and new construction, as well as new medical and financial services. However, new residents may not be fully engaged in the community.

- New wealth and an increasing number of second homes means higher property taxes and other resources for some communities, but it is also creating affordability issues for many.

Young people are moving away because there are no opportunities for them here. Older folks are moving back from the cities for retirement. This means they aren't working the land, thereby reducing productivity and depressing the rural economy. We don't want the Southeast to become a retirement haven.

-Rural practitioner, Southeast region

\section{New rural Americans}

- The wages offered in farm work, agricultural processing, and forestry jobs are often so low that foreign-born immigrants, primarily Hispanics, are either settling in or migrating through many rural areas and performing work that local people once did.

\footnotetext{
${ }^{1}$ Johnson, Kenneth. 2006. Demographic Trends in Rural and Small Town America. Reports on Rural America Volume 1, No. 1. Durham, NH: The Carsey Institute.
} 
- In many situations, these new residents are not establishing roots in an area or community while placing increased demand on community institutions and services without commensurate contributions.

We are starting to see more "in-state based migrants," where migrant workers are establishing homes in one place, and then migrate to farm work from there. We work with documented (30 percent) and undocumented (70 percent) workers in natural resource jobs.

- Rural practitioner, Western Region

- In other areas, immigrants are settling in and making the communities their own and thereby truly rewriting the future of communities and economies.

More Latinos are moving into these communities and opening businesses. Despite some racism and rhetoric against Hispanics immigrants, people here are excited about more children in the schools.

-Rural practitioner, Southern region

\section{Changing Economic Conditions}

Declining resource-dependent areas have been hard hit by globalization and other economic forces. These are "yesterday's" communities, where agriculture, paper and pulp mills, mining, and rural manufacturing sustained a blue-collar middle class and reasonably strong community institutions. Today, new technologies, new business and manufacturing practices, and new global competitors have led to profound changes in rural economies. Many manufacturing operations have relocated overseas, there are fewer large companies, and productivity gains have led to ongoing reduction in the number of jobs and eliminated much of the value-added processing that occurred locally.

With declining economies, more educated and middleclass families are leaving for opportunities elsewhere. These communities are steadily losing population, especially young people. Although rural areas have always lost young people, the impact of global competition means new adjustments, and many rural leaders acknowledge that their communities-especially those in the Northeast and South, which are losing low-skilled manufacturing jobs-are reeling from the loss of jobs and population. ${ }^{2}$ Job loss not only threatens families' livelihoods, but also a community's vitality as key community institutions can no longer be sustained.

\footnotetext{
${ }^{2}$ Glasmeier, A. and P. Salant. 2006. Low-Skill Workers in Rural America Face Permanent Job Loss. Policy Brief \#2 (Spring). Durham, NH: The Carsey Institute.
}

Rural practitioners, however, also see opportunities, especially in entrepreneurship. Many rural development leaders argue that a growing proportion of workers will be self-employed. Jobs in the knowledge and creative economy are also likely to be an increasingly important part of rural America's future. Rural leaders are looking to integrated development approaches, linking economic development to long-term resource management, social, and environmental goals. In addition, medical and financial services hold strong potential. On a deeper level, the core assets of rural areas-land, forests, water, renewable energy resources, and clean air-will continue to underpin the nation's economy and hold strong potential for economic opportunities in rural communities.

\section{Perspectives from the field}

\section{Workforce}

- Pools of skilled labor are insufficient and declining in rural areas. A workforce that can work the land is disappearing.

- Rural communities need more entrepreneurs, and they must attract people who can build new companies and create jobs.

- Technical and educational resources for workforce training are limited, often exacerbated by declining revenues for local schools.

- Several regions of the country are experiencing the effects of a mobile, underclass of migrant workers.

There is an underclass industry of forest workers, and [it] holds wages down for local residents by importing low-wage workers. These people have fewer protections and are easily exploited and can work for less money.

-Rural practitioner, Western REgion

\section{Ownership and investment}

- Absentee ownership and destructive resource extraction of core assets siphon off economic value in some communities and entire rural regions.

- On the other hand, local marketing efforts and cooperatives have the potential to encourage markets for food, wood products, and energy, which can increase return to local economies and benefit communities.

- More targeted local loan and grant programs, and tax and other incentives are needed to encourage locally owned investment. 


\section{Natural resource-based economy}

- Industrialization, consolidation, and globalization have changed the agricultural and forestry sectors, squeezing out smaller farmers, landowners, and operators, depressing wages and prices, and discouraging young people from entering the field.

The paper mill was the largest employer. It was family owned, and the owners had a strong sense of responsibility to their community and its health and stability. In 2000, the mill was bought by a Scandinavia conglomerate. With the change in ownership, we lost corporate philanthropy and local leadership. The company has shifted from being a Corporate 500 family-owned business that identified with its neighbors to one that looks elsewhere for its identity and survival. With globalization, we have also seen a decline in jobs-over 39 percent, the same rate as found in Flint, Michigan.

- Rural practitioner, Midwest region

Large-scale agriculture is growing at the expense of small producers. With the majority of African-American farmers owning 5-20 acre plots, this concentration of land in the hands of a few is hurting our farmers and forcing them out of business. Even the Farm Bill works against us, as subsidies and other benefits are handed out exclusively to the larger producers.

-Rural practitioner, Southeast Region

- Long-term depletion and poor stewardship in fishing have undermined this sector in the East. Poor policy decisions and resource management have led to the downward spiral of fewer fish, fewer jobs, and then even fewer fish. The working waterfront is also feeling development and other pressures.

- Rising oil prices have brought a resurgence in the coal industry, with growing demand for electricians and highly skilled workers. However, with the resurgences comes risk of environmental degradation through destructive land use practices, water and air quality issues, and climate change.
- An economy based on tourism is both a curse and a blessing.

On the positive side, in-migrants are often dynamic, but on the negative side, the tourism economy is a seasonal service economy that pays no benefits. With a resort-based economy, you end up with some very wealthy and a lot of low-income earners.

- Rural practitioner, Western Region

\section{Entrepreneurship}

- Entrepreneurship is a critical driver of economic vitality in rural areas. Creating new, flexible small business development services, loan, grant and tax incentive programs, and technical assistance and educational options can help reverse the long-term drain of entrepreneurial capacity from rural areas.

We set up a Northern Forest loan pool called the Northern Heritage Fund. We bring this fund to areas that need it and look for entrepreneurs, such as someone developing a hut and trail system through the Appalachian Mountains or the Plum Creek developers who are redeveloping Moosehead Lake and creating affordable housing in Greenville. We funded the pool initially from a tax credit deal. The money goes to small business development and affordable housing/facilities.

—Rural practitioner, Northeast region

\section{Renewable Energy}

- Renewable energy (biomass, wind, hydro, solar) holds significant potential for rural communities and their economies, but it is also critical to develop renewable energy industry in ways that truly feed local communities and long-term environmental sustainability.

\section{Changing Patterns of Investment and Resource Distribution}

Major investments in transportation, telecommunications, financial, and other critical services are necessary in many rural areas. However, local tax bases are often unable to support necessary investments and improvements, and the rural topography and remoteness from metropolitan core areas add to the difficulties. According to those interviewed and at the roundtables, decades of inadequate policies and chronic underinvestment have led to growing disadvantage. 
In addition, low education, low employment levels, and racism add to these limited infrastructures and feed persistent poverty in many rural areas, especially in Appalachia, the Delta, the Southwest, and Indian Country. In many of these places, more than 40 percent of adults lack a high school degree, and are ill prepared to compete in a global economy. These communities are politically marginalized, with a weak voice on the national stage. The challenges for children and families in these communities are enormous, and policies that support investment in human and social capital are of primary importance. Some regions, however, are seeing improvements in rural health care and education, and bestpractices models are emerging.

\section{Perspectives from the field}

Transportation, telecommunications, and child care

- Public transportation is sorely lacking.

Investment is made in roads, which is fine for people with cars, but not all people have cars. There is a minimum investment made in public mass transportation. This means poor folks can't get to health care, jobs, and other services which are often over 20 miles away.

-Rural practitioner, Western region

- Expanded broadband telecommunication is essential if rural areas are to be competitive in a global economy.

- Limited access to child care restricts rural residents' ability to work.

\section{Housing}

- In some areas, rural housing has deteriorated and is at greater risk of damage from extreme weather and indoor air pollution. Current programs to build affordable housing have limited funding and do not support single family homes. Subsidized loans for housing help only the very poor.

\footnotetext{
Government support for affordable housing is like "tokenism." It is never enough to make a difference in a community. All a community can get through subsidies is 6 to 15 houses a year. This is a token gesture by the government to say they care about economic means.

-Rural practitioner, Southeast Region
}

- Models for building affordable homes at market rates that will build assets exist and should be expanded and applied.

\section{Education}

- Poor quality education and after school programs are limiting the future for rural children. Dependence on timber revenue to support schools and roads has left certain areas with limited education funding.
A decline in timber revenues by $90 \%$ has caused the vast majority of schools in the county to operate on a four-day school week. The money from timber revenues from national forest land would typically go back to rural communities and is prioritized for rural schools and roads. There has been a massive reduction in payments. This four-day work week accelerates problems with child care.
-Rural practitioner, Western region

- Regional universities and technical and community colleges can help in revamping workforce development and other aspects of rural education.

\section{Health care}

- The health sector is handicapped by limited availability and accessibility and inadequate funding of basic services, as well as the perennial shortage of health care providers.

The loggers and sawmills used to help support the rural hospitals. Without these jobs, there isn't private money anymore to support hospitals. These communities are losing hospitals and county doctors. In isolated communities, as the population grows older, residents need to live near specialists.

- Rural practitioner, Western region

We are in a health crisis, with more tribal members having irreversible and chronic illnesses than ever before. Yet, the Indian Health Services spends less on a per capita basis on Native Americans than it does on the prison population. There isn't enough care, and it's not quality care.

- Rural practitioner, Southwest REgion 


\section{Infrastructure}

- Water and wastewater systems are in disrepair and at the limits of their capacity in some rural areas. However, funding for improving this outdated infrastructure has declined.

There are a lot of unincorporated communities in the state which have access to water problems. These are historically African American areas and they are still not extending services to these areas. This is still the shameful situation in North Carolina. African American communities are still relying on well water and small companies.

- Rural practitioner, Southeast region

\section{Finance}

- Predatory lenders, payday loans, and other such financial practices prey on people with limited means in rural areas.

- Small business development programs are sometimes inaccessible to rural entrepreneurs because they require significant financial resources, such as match requirements, to access these programs.

\section{Prejudice}

- Prejudice against African Americans and Native Americans continues to restrict opportunities.

Native people have all the negative social indicators-dropout rates are high, education is low, health is poor, violence on Native women by non-Natives is high. Social and economic facts plague these communities. The average life expectancy for Native people is 60 years old. Life is short because of health issues and a history of brutality that has contributed to alcoholism and drug abuse. It is a culture impacted by racism.

-Rural practitioner, Western region

Not only do we lack access to quality education, but we also suffer an increasing and higher "push-out" rate compared to other populations Current "no tolerance" rules-combined with racism-result in more African-American students being "pushed-out" from school. We need to put "due process" back in place when addressing issues of violence, misbehavior, and substance abuse.

-Rural practitioner, Southeast Region

\section{Challenges Facing Community Institutions and Civic Leadership}

The rapid rate of change, declining effectiveness of traditional economic strategies, increasing environmental challenges, and demographic transitions require leadership to guide the community in new ways of thinking and doing. Respondents called for leaders to be visionary and to see the potential in their communities; they must also be risk takers, able to create and respond to opportunities, and they must identify and use the assets within their own communities, rather than relying on dwindling and often inappropriate external assistance. Some respondents described their communities as conservative and risk-averse, places where calling for change and action is not part of the civic culture. The old leadership cadre is often resistant to change, accustomed to traditional ways of doing things that worked well for them in the "old economy." New approaches of sharing power and bringing in younger and more diverse voices are threatening to them. Many describe county officials as remote from community affairs, more overtly political, and often dominated by big business. Democracy in some rural communities is weak, with a politics of "who you know," rather than one based on issues. Some local communities have lost trust in local and larger government, and public participation has diminished.

\section{Perspectives from the field}

The need to for local leadership in the public and civic sector

- In more remote areas and in the smallest communities, county and state governments have come to play a larger role, yet these public entities are rarely accountable to local residents. Programs may be applied ineffectively and are frequently not adapted to local needs. Community members lack the capacity to make these agencies work for them.

We have become more dependent on the outside, thinking that someone else should pay, do, solve, rather than looking at our own human capital and assets. It's a case of learned helplessness!

-Rural practitioner, Appalachia Region

Rural residents are very dependent on federal, state, and county agencies-yet they don't have the capacity to make these agencies work for them, which means that the agencies only help them as far as the agencies see fit, which may not be in the residents' best interest.

- Rural practitioner, Southwest Region 
- Skills, knowledge, and infrastructure are needed to enable communities to rely more on internal resources, rather than outside forces. Building self-reliance and capacity through local leadership and community institutions is critical to eliminating dependency.

There is an overall inability of rural residents to direct their destiny. Without self-determination at the local level, we are forced to live with "other determinants."

-Rural practitioner, Southwest Region

Our vision is that capacity is built within the communities to address community problems. We are growing leadership to shift the culture from dependence on one or two large employers to one of independence and interdependence. We are engaging the community to develop the vision and see that they have control and responsibility in making that vision happen.

-Rural practitioner, Midwest region

We need citizens-the real people that are the object of the policy-to monitor if intent of the policy is being carried out and whether it is implemented the same for all rural communities. We need to strengthen leadership skills and strong community institutions to ensure a voice for these constituencies.

-Rural practitioner, Southeast region

Leadership is underdeveloped, which is a constant barrier to using opportunities and keeps us thinking small. We don't have a culture that rewards the risk-taking needed for visionary leaders to emerge. We need to invest in youth as leaders.

-Rural practitioner, Appalachia Region

There is a lack of African-American leadership starting at the grassroots and moving up to the state and nationally. Few leaders are representing the communities and their interests-or feel accountable to them-and therefore no resources are being driven back to the communities.

- Rural practitioner, Southeast region

\section{Environmental Challenges}

Long-standing environmental problems plague many rural areas, and in some cases are worsening. Industrial agriculture and forestry have taken a toll on the integrity of large ecosystems and the future productivity of the land. New environmental challenges, such as sprawl and land fragmentation, are increasing with rapid population growth and new ownership and land use patterns.

Overshadowing all other issues is climate change, which is introducing unprecedented stress on ecosystems and the communities that depend on them. From impacts on overall ecosystem health to changes in sea-level and storm impacts, to consequences for agriculture, forestry, recreation, and tourism, climate change is a growing concern for rural communities across the country. However, rural leaders are also hopeful that new sustainable practices, such as organic agriculture and alternative fuel development can help to drive economic development.

\section{Perspectives from the field}

\section{Strain on the resource base}

- Extractive industries have devastating environmental impacts. When plants close they leave behind environmental contamination. Lack of funding prevents necessary watershed restoration work.
Coal has been a major factor in a renewed interest in resource extraction. Native communi- ties may have ownership of the resources, but corporations from the outside come, extract, and leave a mess. There is a Navajo ban on uranium mining.
-Rural practitioner, Western Region

- The demand for cheap food lowers prices for farmers, who try to make up for the low price in volume. This leads to ecological stresses on the resource base, and ultimately degrades it.

New sustainable economic options

- Ecosystem services such as biodiversity, clean air, clean water and alternative energy can create revenue for natural resource based economies.

- A restoration economy-repairing damage to forests through intensive hands-on management and restoring ecosystems form natural disasters-has potential for employing young people, building skills, and reconnecting people with the land in rural areas. 
- Ecotourism holds potential as an economic development strategy.

- Rural communities are focusing on an expanding market for environmentally certified or organically produced products.

Tobacco used to be profitable, when the price went down it created opportunities. Tobacco farmers are transitioning to becoming organic farmers.

- Rural practitioner, Southeast region

\section{Ecosystem fragmentation}

- Land fragmentation occurs when large private or industrial owners sell for development on smaller parcels for homes or other uses. Land conversion undermines the long-term potential for agriculture and forestry in broad regions.

There are private land issues when in-migrants buy the land and cause forest fragmentation for ranchettes. These people don't take care of their land, there's been a philosophical shift about what land is used for. If you want to live in Eden, then who is your gardener?

-Rural practitioner, Western region

The value of forestland has changed. The value to have and hold private forestland is diminished as the value of land rises for real estate development. The incentive now is to convert the land. People want clear-cut land with gorgeous views. As a lot more private land becomes available, there is industrial conversion.

- Rural practitioner, Western region

- Environmental regulations sometimes conflict with rural development efforts, as when environmental litigation closed down the forest for protection of the spotted owl or when "one-size-fits-all" USDA forest policy undermines local resources and degrades the forest.

\section{Emerging Visions and Strategies for Change}

From their particular geographic and social perspectives, and from their visions of what is possible in rural communities, rural practitioners offered an array of ideas and strategies for addressing the challenges in rural America. One thing is clear: developing effective public policies to implement a new generation of rural strategies cannot be done piecemeal. Rural interests require a broad perspective and connections with other regions and national policymakers to forge and implement a dynamic and effective program for rural America. The following strategies and vision reflect emerging opportunities that the National Rural Assembly may consider. Each set of recommendations for demographic transition, economic development, community and infrastructure, civic leadership and environmental stewardship begins with a vision of what a vibrant rural America could be, followed by the strategies to achieve that vision.

\section{Demographic Transitions}

Vision: Communities have a vibrant mix of young, mid-life, and older residents supporting dynamic and resilient communities.

Strategies:

- Support migrants' ability to integrate into rural communities

- Provide quality educational resources to attract and hold young families

- Implement policies to provide affordable mixed-income housing

- Support the ability of rural people to own and live on the land, especially in high-amenity areas or areas where large industries own much of the land

\section{Changing Rural Economies}

Vision: Local economies are diversified and linked to local, regional, national and international markets. These economies are based in local ownership and local control of core assets, include community and regionally scaled food and energy systems, and offer local employment opportunities that provide a living wage and the resources to sustain communities. 
Strategies:

- Identify economic opportunities to draw and hold young people and families

- Contribute to secure, renewable, local sources of energy through agricultural and other forms of biomass

- Revamp education institutions to provide effective, relevant workforce training and development and that support entrepreneurship

- Provide small business development services

- Implement federal policies that benefit rural communities rather than industrial agriculture and those producing commodities (for example, through changes in the Farm Bill)

- Support development of regional markets and encourage local production for local markets

- Support place-based products, recreation, and tourism

\section{Investment in Community Institutions and Infra-} structure

Vision: Communities have effective infrastructure and institutions that serve residents, build strong families and communities, and support equitable access and opportunity for all residents.

Strategies:

- Support secure and adequate funding for rural schools

- Create an effective rural health care infrastructure that provides good access to services, including mental health and substance abuse treatment

- Provide affordable, high-quality child care in rural communities

- Invest in affordable, broadly available rural transportation

- Create comprehensive rural broadband telecommunications access

- Restructure delivery and implementation of government services to ensure equitable access, including access to critical services, such as education, health care, legal and financial assistance to immigrant and migrant workers

- Change federal contracting practices (H2B) to provide more equitable treatment and fair wages and benefits to immigrant and migrant workers

- Develop performance measures for federal agency policies and capacity to monitor compliance

- Invest in federal disaster readiness capacity

- Establish fair rural compensation rates on federal and other publicly funded services

\section{Building New Civic Leadership}

Vision: Communities have the capacity to meet needs through strong civic leadership, mutual respect, and commitment to multicultural values.

Strategies:

- Provide funding and support for local capacity-building

- Conduct bottom-up policy development, and create collective processes for problem-solving at the community level

- Develop better partnerships with state universities to facilitate leadership training and community capacity building tailored to the needs of proximate communities

- Implement programs that assure a "seat at the table" for local leaders when regional policies are being set.

\section{Environmental challenges}

Vision: Communities have an ethic of stewardship for the land and the people that live there, and long-term environmental and economic health are integrated.

Strategies:

- Reform agricultural and energy policy to address climate change

- Reform U.S. forest policies and practice; develop community-level programs

- Approach forestry with a different twist: not cords and boards, but more diverse goals integrated with environmental goals and ecological services

- Continue existing, effective USDA forestry programs: Community Forestry Restoration Act, Rural Development through Forestry, and the Economic Action Program

- Provide consistent multiyear funding for federal programs

- Invest in federal forest management for timber, fire control, and recreational infrastructure 


\section{In Summary}

Rural America in the twenty-first century must develop new relationships and new ways of doing things to ensure an economically prosperous, socially just, and environmentally healthy future. Tapping into the resourcefulness and creativity of rural people will be essential in addressing this challenge. However, they cannot do it alone. Rural communities need critical infrastructure, investment, capital, and services.

There is a need to engage the real people that are the object of the policy to monitor whether the intent of the policy is being carried out and whether it is being implemented the same for all communities. We need to strengthen leadership and skills to be able to accomplish this.

-Rural practitioner, Southeast region

Why should we have policies that say rural communities should have anything less than strong education, health care, and economic opportunities on the land? We need good policies, but we also need the power to make things happen-or prevent them from happening.

-Rural practitioner, Southeast region

In the absence of the people who are the ones who live and work in rural communities being involved in policy decision processes, real change or real solutions won't be found.

- Rural practitioner, Western region

The overlapping forces shaping rural America-demographic transitions, economic changes, the legacy of chronic underinvestment in community institutions, and environmental factors - present challenges and opportunities. With the voices and strategies of rural Americans in hand, the National Rural Assembly can now move forward toward this vision for a twenty-first century rural America.

\section{Interviewees and Participants}

\section{New England Regional Roundtable}

John Bartow, NYS Tug Hill Commission

Jeff Campbell, Ford Foundation

Catherine McDowell, Gorham Family Resource Center

Carla Dickstein, Coastal Enterprises, Inc

Bruce McLean, Millinocket Area Growth and Investment Council (MAGIC)

Paul Parker, Cape Cod Commercial Hook Fishermen's Association

Minor Sinclair, Oxfam America

Christopher (Kit) St John, Maine Center on Economic Policy

Peter Taylor, Maine Community Foundation

Bill Webb, Northern Forest Center

\section{Appalachia Regional Roundtable}

Lisa Abbott, Kentuckians For The Commonwealth Angie Cantrell, ACEnet

David Cooke, Entrepreneurship for the Public Good/ Appalachian Fund

Colin Donohue, National Network of Forest Practitioners Peter Hille, Brushy Fork Institute

Ron Hustedde, UK Community \& Leadership Development James King, Federation of Appalachian Housing Enterprises Tim Marema, Center for Rural Strategies

Justin Maxson, MACED

Tom Miller, Consultant

Judy Owens, MACED

Gerry Roll, Hazard Perry County Community Ministries

Herb Smith, Appalshop

Robin Stewart, Ohio University's Voinovich School

Mary Steinmaus, Rural Action

\section{Southwest Regional Roundtable}

Phil Archuleta, P \& M Signs

Henry Carey, The Forest Guild

Carl Colonius, Rocky Mountain Youth Corps

Craig Conley, Quivira Coalition

Howard Gross, The Forest Guild

Sam Gutierrez, Entrepreneur

Dwayne Lefthand, Taos Pueblo Tribal Government

Peggy McCracken, Science Teacher

Reuben Montes, USDA Forest Service-Santa Fe National Forest

Jan-Jay Moolenijzer, Walatowa Woodlands Initiative Ignacio Peralta, USDA Forest Service-Carson National Forest 
Robert Potts, USDA Forest Service-Santa Fe National Forest

Orlando Romero, The Forest Guild

Ben Sanchez, La Jicarita Enterprise Community

Juan Sanchez, Entrepreneur

Miguel Santistevan, New Mexico Acequia Association

Louis Torres, Torres Consulting

Delbert Trujillo, Environmental Consultant

Gilbert Vigil, Entrepreneur

Jake Vigil, Entrepreneur

\section{National Rural Assembly Interviewees}

Lucas Benitez, Coalition of Immokalee Workers, Inc.

Henry Carey, The Forest Guild

Nils Christoffersen, Wallowa Resources

Carla Dickstein, Coastal Enterprises, Inc.

Colin Donohue, National Network of Forest Practitioners

Maia Enzer, Sustainable Northwest

Anthony Flaccavento, Appalachia Sustainable Development

Savi Horne, Land Loss Prevention Program

Leroy Johnson, Southern Echo

Diana Jones Wilson, Faith Partnerships

Lynn Jungwirth, Hayfork Watershed and Research Center

James King, Federation of Appalachian Housing Enterprises

Connie Loden, Heart of Wisconsin Business and

Economic Alliance

Kelly Lucas, Community Foundation of Southwood County Jason McKenzie, North Gulfport Community Land Trust

Sungnome Madrone, Madrone Enterprises

Justin Maxson, MACED

David Morris, Institute for Local Self-Reliance

Melanie Parker, Northwest Connections

Paul Parker, Cape Cod Commercial Hook Fishermen's

Association

Chris Peters, Seventh Generation Fund

Ramon Ramirez, PCUN (Northwest Treeplanters and

Farmworkers United

Tristan Reader, Tohono O'odham

Denise Smith, Alliance of Forest Workers and Harvesters

John Squires, Community Resource Group

Frank Taylor, Federation of Southern Cooperatives
A B OUT THE CARSEY INSTITUTE The Carsey Institute at the University of New Hampshire conducts research and analysis into the challenges facing rural families and communities in New Hampshire, New England, and the nation. The Carsey Institute sponsors independent, interdisciplinary research that documents trends and conditions in rural America, providing valuable information and analysis to policymakers, practitioners, the media, and the general public. Through this work, the Carsey Institute contributes to public dialogue on policies that encourage social mobility and sustain healthy, equitable communities and strengthens nonprofits working to improve family and community well-being. The Carsey Institute was established in May 2002 from a generous gift from alumna and noted television producer Marcy Carsey.

\section{ABOUT THE AUTHORS}

The research team for this report included Andrea Colnes, Curt Grimm, Amy Seif Hattan, and Nena Stracuzzi from the Carsey Institute and Barbara Wyckoff-Baird, consultant to the Institute.

\section{$\triangle$ UNIVERSITY Ai of NEW HAMPSHIRE}

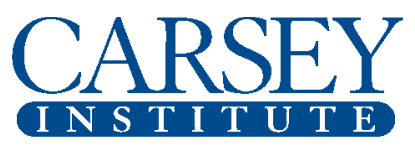

Building knowledge for families and communities in the 21st Century.

The Carsey Institute at the University of New Hampshire conducts independent, interdisciplinary research and communicates its findings to policymakers, practitioners and the general public.

Huddleston Hall

73 Main Street

Durham, NH 03824

(603) $862-2821$

www.carseyinstitute.unh.edu

Rural America in the 21st Century: Perspectives from the Field is supported by the Ford Foundation. 